\title{
AN OVERVIEW OF THE CONNECTION CLASSIFICATION INDEX
}

\author{
Iman Faridmehr ${ }^{1 *}$, Mahmood Md. Tahir ${ }^{2}$, Mohd Hanim Osman ${ }^{3}$, Abbas Razavykia ${ }^{4}$ \\ ${ }^{1}$ South Ural State University, 454080 Chelyabinsk, Lenin Prospect 76, Russian Federation \\ ${ }^{2}$ UTM Construction Research Centre (CRC), Institute of Smart Infrastructures and Innovative Construction, School of Engineering, Universiti Teknologi Malaysia (UTM), \\ Skudai, Johor Bahru, 81300, Malaysia \\ ${ }^{3}$ Forensic Engineering Centre (FEC), Universiti Teknologi Malaysia (UTM), Skudai, Johor Bahru, 81300, Malaysia \\ ${ }^{4}$ Department of Mechanical and Aerospace Engineering, Politecnico di Torino, Corso Duca degli Abruzzi 24, 10129 Torino, Italy \\ *(Corresponding author: E-mail: s.k.k-co@live.com)
}

\section{A B S T R A C T}

This research evaluated the beam-to-column connection classification index recommended by Eurocode 3 Part 1.8 and ANSI/AISC 360-10 specifications. A test programme was considered to examine the moment-rotation (M- $\theta$ ) curve of semi- and fully rigid connections with variable parameters. The maximum moment capacity and initial elastic stiffness of the connections were the main parameters resulting from the $\mathbf{M}-\theta$ curve. The performance of beams with semi-rigid connections was also evaluated through a classical method. The results clearly showed that the Eurocode 3 specification provides a more reliable classification index for the investigated connections. By evaluating the data of this research, a new classification system based on the rigidity, ultimate strength level, and ductility requirements was proposed. The results of this research provide an important contribution to the existing literature as the actual responses of beam-to-column connections are semi-rigid, and therefore such behaviour should be included in the analysis and design method.
ARTICLE HISTORY

$\begin{array}{ll}\text { Received: } & \text { 29 October } 2017 \\ \text { Revised: } & 25 \text { July } 2018 \\ \text { Accepted: } & 1 \text { August } 2018\end{array}$

\section{K E Y W O R D S}

Moment-rotation (M- $-\theta)$ curve Semi-rigid connections; Classification system; Stiffness; Ductility

\section{Introduction}

In the traditional design of structures, the actual performance of beam-tocolumn connections is idealized and categorized into two groups: Fully Rigid "FR" connections and flexible connections. In real situations, however, neither idealized group is realistic as the majority of beam-to-column connections show semi-rigid performance that represents a third category, the so-called Partially Restrained "PR" connections. According to the majority of design regulations, it is only compulsory to consider the flexibility of connections for the third category, even though it is evident that ideal connection behaviour can be put in this category in some way. It is also important to consider that increasing connection flexibility results in significant second-order $(\mathrm{P}-\Delta)$ in the frame that should be accounted for during the design process. Furthermore, the rotational distortion of the connections affects the displacements of the frame and causes redistribution of moments between columns and beams. Thus, identification of the actual flexibility of steel beam-to-column connections is a crucial need in the design and analysis procedure of steel structures.

The main problem in developing a connection classification index is the need to provide criteria that can meet the requirements of serviceability as well as the ultimate limit states design. With regard to the serviceability issue, the main concerns are the rotation and other stiffness-related features. With regard to the ultimate limit issue, the strength limits are the main parameter. The energy absorption capacity, ductility, and rotation are critical aspects of structures that are located in seismic regions. In both ANSI/AISC 360-10 [1] and Eurocode 3 Part 1-8 specifications [2], three categories of connections are defined, namely flexible connections, rigid connections, and semi-rigid connections. The basic assumption in classifying connections is concerned with the moment-rotation $(\mathrm{M}-\theta)$ curve characteristics. A simple connection transmits a negligible moment; however, it is supposed to have adequate rotation capacity to resist the required rotation. A fully rigid (FR) connection transfers the moment with a small rotation between the beam and column. Partially restrained (PR) connections transfer moments; however, the rotation between the beam and column should be considered during the design process. Accordingly, connection components should have sufficient stiffness and strength capacity. From the perspective of the Moment-Rotation, defining the sections in the $\mathrm{M}-\theta$ diagram by nonlinear curves is adequate. This fact is shown in Fig. 1, where three basic responses are indicated.

AISC seismic provisions claim that all prequalified connections such as bolted unstiffened, stiffened extended end-plate (EEP), bolted flange plate (BFP), and SidePlate moment connections are FR for use with special moment frames (SMFs) and intermediate moment frames (IMFs) when designed and constructed in accordance with the requirements of AISC. The availability of a large database on the actual $\mathrm{M}-\theta$ characteristics of various connections makes it possible to conduct extensive verification of the rigidity and classification

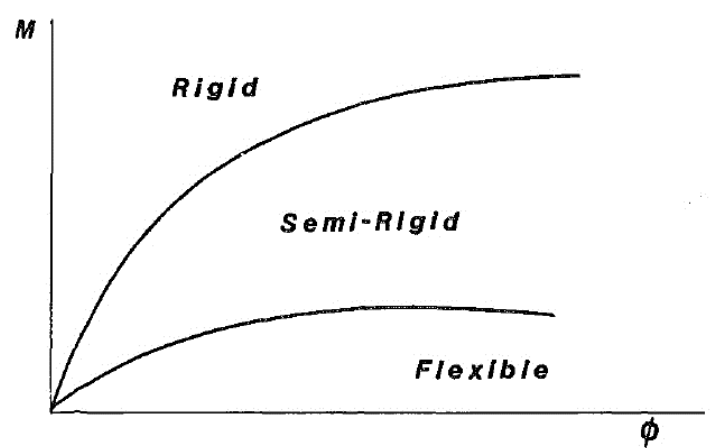

Fig. 1 Basic nonlinear connection response regions

indices proposed by AISC and Eurocode 3 "EC3". To this end, over the past few decades, a great deal of effort has been expended within the research arm of the structural engineering profession to address the topic of classification of connections and their impact on the structural response [3-10]. These analyses mainly involve the calculation of stiffness and strength from the experimental M- $\theta$ curve, which is validated using Finite Element analyses. There are many published works describing continued and even expanded work on this issue, especially with regard to semi-rigid connections [11-19]. These studies mostly consider the effect of semi-rigid joints on the structural performance of frames. In recent years, Talebi et al [17], Concepción Díaz et al [20], Zahmatkesh et al. [21] suggested a new method for the optimum design of semi-rigid steel connections using kriging and Latin hypercube approaches. This methodology was applied to two examples involving bolted EEP connections. A unique technique for 3D semi-rigid steel frames was developed by Nguyen and Kim [22]. In their technique, connections were defined by 3D nonlinear spring elements to consider the distribution of plasticity effects. The response of semirigid bolted connections under cyclic loading was investigated by Brunesia et al. [23]. In their study, examples of full-scale moment-resisting connection systems were numerically analysed, focussing on top-and-seat angle components which were observed to control the global response of the joint in terms of the failure mechanisms, dissipation energy capabilities, and ductility capacity of the whole resisting system.

In previous works, researchers have proposed a connection classification 
index, which is generally obtained from the $\mathrm{M}-\theta$ curve. The results of these studies provide major contributions to the EC3 Part 1-8 and ANSI/AISC 36010 regulations. This paper aims to evaluate the adequacy of the connection classification index proposed by AISC and EC3. This task is carried out by conducting experimental tests on EEP and SidePlate beam-to-column connections with variable parameters. The proposed classification system was also arranged using tests and theoretical data such that the abovementioned connections can easily fit into the proposed classification system.

\section{Connection Response Considerations}

The responses of flexible or semi-rigid connections when subjected to gravity loading are investigated in this part. For a beam segment with rotation at each end, the moment, Mbeam, is calculated based on the following equation:

$$
M \_b e a m=2 E I / L \theta-\left(w l^{\wedge} 2\right) / 12
$$

\section{where}

$\mathrm{L}$ and $\mathrm{I}$ are the length and second moment inertia of the beam, respectively,

$\mathrm{E}$ is the elasticity module.

In beams with flexible connections, the moment and rotation based on Eq. 1 are calculated as 0 and $\left(W l^{\wedge} 3\right) / 24 E I$, respectively. For a Fixed End Moment situation considering rotation equal to 0 , it is found that $M_{-}$beam $=$ $-\left(w l^{\wedge} 2\right) / 12$. The linear relationship between the rotation and moment at the end of the beam is found by plotting Eq. 1, as shown in Fig. 2 .

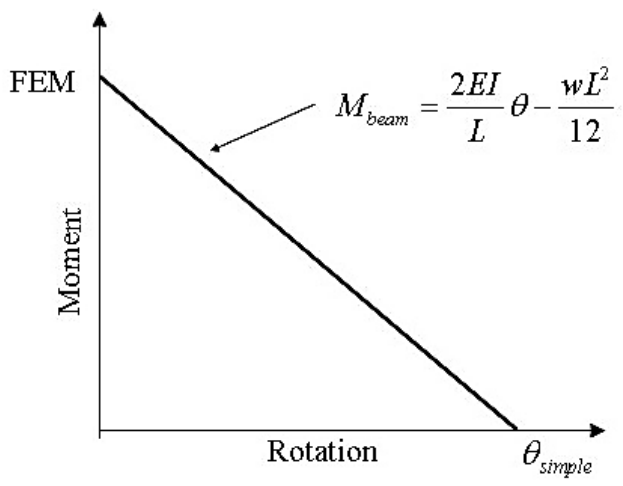

Fig. 2 Rotation versus moment for a beam with flexible and fixed connections

On the other hand, the moment in the connection, Mconn, has a relationship with the connection stiffness and rotation, as illustrated in the Eq. 2 and presented in Fig. 3:

$$
M_{-} \operatorname{conn}=-n \theta
$$

where

$\mathrm{n}$ is the connection rotational stiffness.

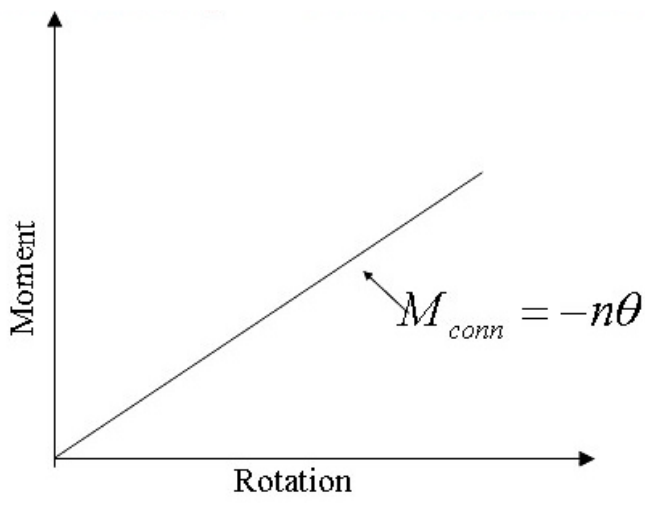

Fig. 3 Rotation versus Moment for Connection

The $\mathrm{M}-\theta$ diagram is a straight line, but it does not behave linearly forever, and at a particular point it will experience failure. Fig. 4 shows the moment versus rotation for different connection types that are combined by a typical beam line. Geschwindner [24] showed that as long as the connection resists more than $90 \%$ of the moment of the fixed connection, it is possible to classify it as rigid; on the other hand, those connections that resist less than $20 \%$ of the moment of the fixed connection should be classified as flexible, as shown in Fig. 4. Any performance between these two categories is considered as a semi-rigid connection.

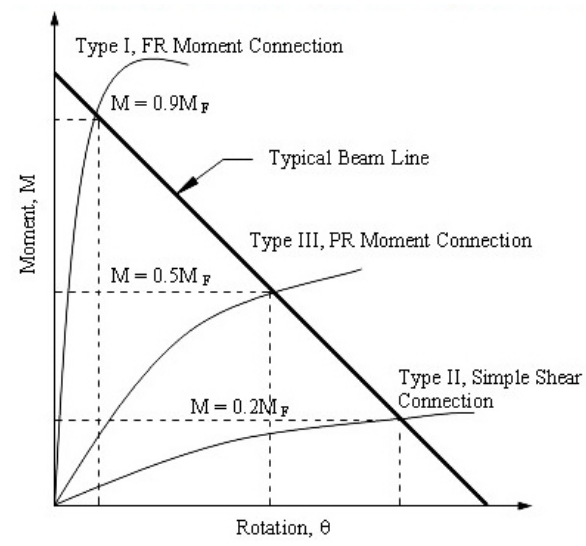

Fig. 4 Beam-to-Column connection classification based on moment resistance [24]

Geschwindner [24] also investigated the superposition of the straight line of FR, semi-rigid, and flexible connections on the typical beam line, as shown in Fig. 5. He calculated the secant stiffness of the connection, $k_{i}$, at 90, 50, and $20 \%$ of the stiffness of a beam with a rigid end, based on the following equation:

$k i=M i / \theta i$

where

$\mathrm{M}_{\mathrm{i}}=$ moment at the intersection of a straight line with the beam line $(\mathrm{kN}$ $\mathrm{m})$,

$\theta i=$ rotation at the intersection point with the beam line $(\mathrm{rad})$.

Finally, he proposed three categories by solving the following equation:

$(k i L) / E I$

By solving Eq. 4 for the secant stiffness of the connection, $k_{i}$, at 90,50 , and $20 \%$ of the stiffness of a beam with a rigid end, values of 18,2 , and 0.5 were calculated, respectively.

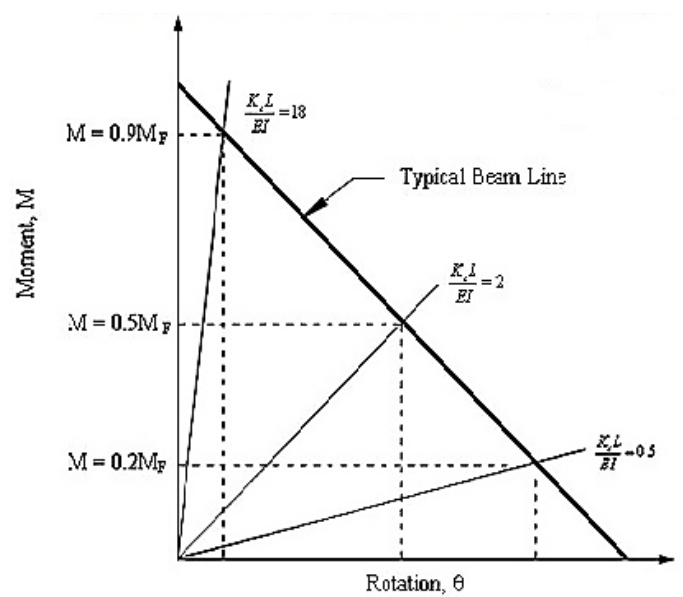

Fig. 5 Beam and connections equilibrium using the secant stiffness [24]

\section{Classification Index Proposed by Eurocode 3 and AISC}

\subsection{AISC 360-10 Classification}

The AISC classifications consider the stiffness, ductility, and strength of beam-to-column connections. The stiffness at service load, KS, is defined by the following equation:

$K s=M s / \theta s$

where

$\theta \mathrm{s}=$ rotation at service load $(\mathrm{rad})$,

$\mathrm{Ms}=$ moment at service load $(\mathrm{kN}-\mathrm{m})$. 
If $\left(k s L_{b}\right) /\left(E I_{b}\right) \geq 20$, the connection is considered to be FR. Accordingly, it is able to maintain the angles between the connected members. If $\left(k s L_{b}\right) /\left(E I_{b}\right) \leq 2$, the connection should be considered flexible as it rotates without increasing the moment. These two boundaries are presented in Fig. 6. Those connections having a stiffnesses between these two boundaries are semirigid and the stiffness of the connection should be defined in the analysis process.

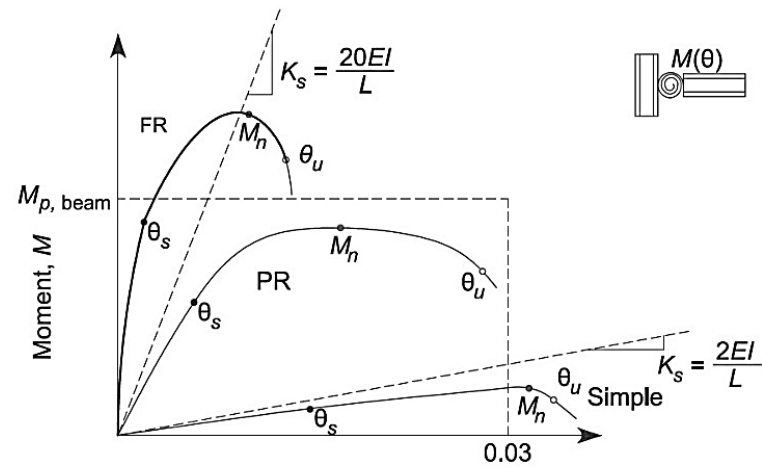

Rotation, $\theta$ (radians)

Fig. 6 AISC connection classification [1]

The strength of a connection is the maximum moment that it is capable of carrying, $M_{n}$, as shown in Fig. 6 . If the $M-\theta$ response does not exhibit a peak load, then the strength can be taken as the moment at a rotation of $0.02 \mathrm{rad}$ [25]. Those connections that transfer less than $20 \%$ of the connected beam plastic moment, $\mathrm{M}_{\mathrm{p}}$, at a rotation of $0.02 \mathrm{rad}$ should be considered to have no flexural capacity.

The ductility required for a connection will depend upon the particular application. For example, the ductility requirement for a braced frame in a nonseismic area is generally less than the ductility required in a high seismicity area. Generally, in a situation where the connection strength exceeds the beam strength, the ductility of the whole system is governed by the beam and the connection remains elastic. If the connection capacity exceeds the beam capacity slightly, the connection experiences plastic deformation before the connected beam experiences its full capacity. If the beam capacity exceeds the connection capacity, then deformations only take place in the connection itself. In Fig. 6, the rotation capacity of the connection, $\theta_{\mathrm{u}}$, is defined by the rotation at the point where either (i) the connection resistance has dropped to $0.8 \mathrm{M}_{n}$ or (ii) the deformation is more than $0.03 \mathrm{rad}$.

\subsection{Eurocode 3 Part 1-8}

Eurocode 3 classifies connections by considering their stiffness and strength. The initial rotational stiffness, Sj.ini, will be compared to the classification boundaries shown in Fig. 7. Connections classified as FR are assumed to have adequate rotational stiffness to carry out an analysis based on full continuity. In Fig. 7, zone 1 is representative of a FR connection if

Sj ini $\geq\left(K_{b} E I_{b}\right) / L_{b}$

where

$\mathrm{K}_{\mathrm{b}}$ is 8 for braced frames or 25 for moment-resistant frames.
A flexible connection transfers the internal forces without developing moments. Based on Fig. 7, the connections are considered flexible (zone 3) if

$$
\text { Sjini }) \leq\left(0.5 E I_{b}\right) / L_{b}
$$

A connection that does not address the criteria of FR and flexible connections is categorized as semi-rigid (zone 2). According to this regulation, semi-rigid connections are capable of transferring the shear forces and moments.

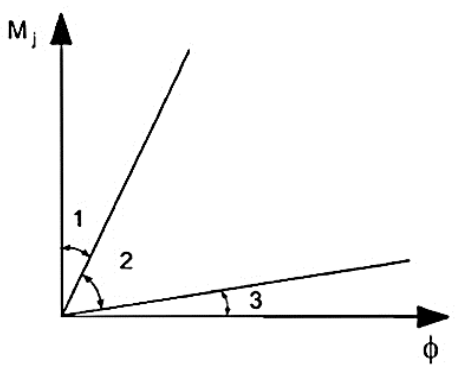

Fig. 7 Eurocode 3 Connection Classification Boundaries

The initial rotational stiffness, Sj.ini, is calculated from the flexibilities of the connection's basic components, each characterized by a coefficient, ki. For instance, $\mathrm{Sj}$.ini is determined from the following equation for end-plate connections:

$S_{j}=\frac{\mathrm{E} z^{2}}{\mu \sum_{i} \frac{1}{k_{i}}}$

where

$\mathrm{k}_{\mathrm{i}}$ is the stiffness coefficient for the basic joint component $\mathrm{I}$,

$\mathrm{z}$ is the lever arm,

$\mu$ is the stiffness ratio $\left(S_{j}\right.$ ini $\left./ S_{j}\right)$.

\section{Test Rig and Case Studies}

For full-scale experimental testing, a test rig for a cantilever beam with a 1.3-m span and a column 1-m high was employed. The reacting frame was constructed by using wide channel sections with 22-mm holes that were attached to the strong floor of the laboratory (Fig. 8). The columns were restrained from lateral movement at both ends. The beam was also restrained from lateral movement in the middle. The concentrated load was applied by a hydraulic jack at the tip of the beam. To simulate quasi-static loading, a monotonic push-down loading was employed in which the loading was accomplished by using 5-kN increases until significant deformation of the beam occurred. After that, the increase in the vertical displacement of the beam controlled the loading segments, as a small increment led to a substantial increase in deflection. This loading protocol continued until failure of the specimen. Failure was recognized once a quick or substantial decrease in the applied load or a significant vertical displacement occurred. An inclinometer was attached in the connection shear panel zone to measure the rotational deformation. Moreover, the vertical deflection of the specimen was measured using a linear LVDT installed at the tip of the beam.
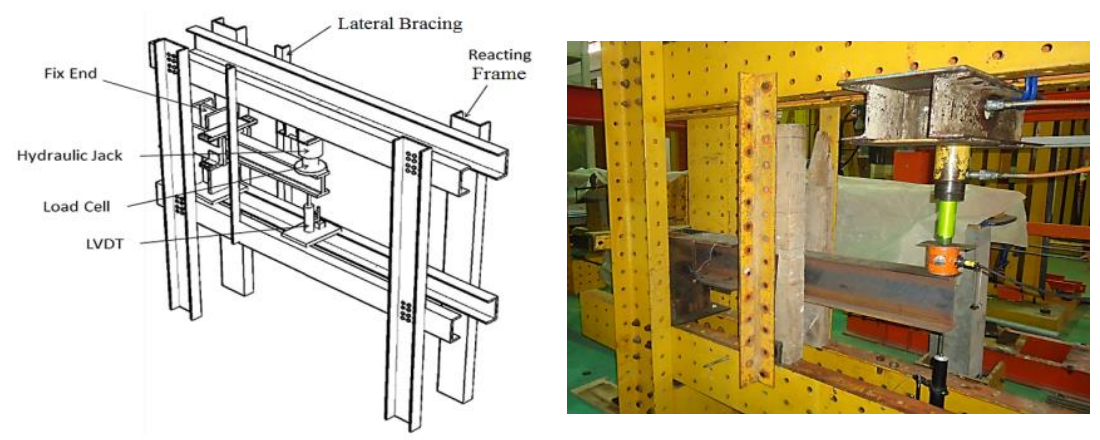


\subsection{Case Studies}

Eight unstiffened EEP connections were arranged for testing. According to Eurocode 3 Part 1.8, in EEP connections, an equivalent T-stub in tension is considered to calculate the capacity of basic components. A T-stub consists of a bending-loaded flange and tension-loaded web, as shown in Fig. 9. The screw axes are subjected to tension that is counteracted by supporting forces at the outer edges, which are idealized as rigid supports. The T-stub model differentiates three failure modes: first, failure of the bolts and yielding of the flanges; second, full yielding of the flanges; and third, failure of the bolts [26].
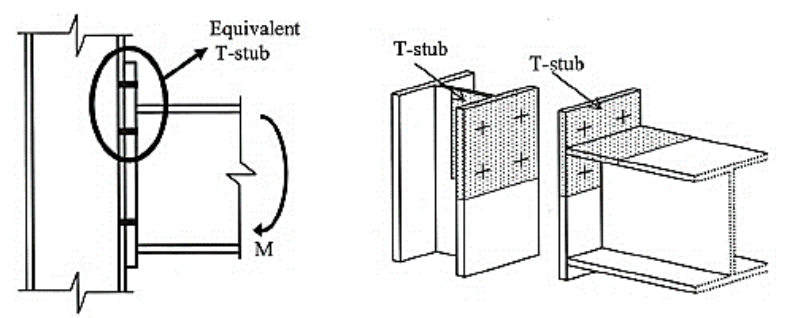

Fig. 9 Definition of T-Stub and Orientation
In this study, the connection components were selected according to the norms and practices of existing steel structures in Malaysia. Besides, as the country is located in a low seismic zone and has not experienced a severe earthquake so far, the connection is only designed to resist gravity loading, and continuity plates were omitted. Fig. 10 highlights the configuration of the connection.

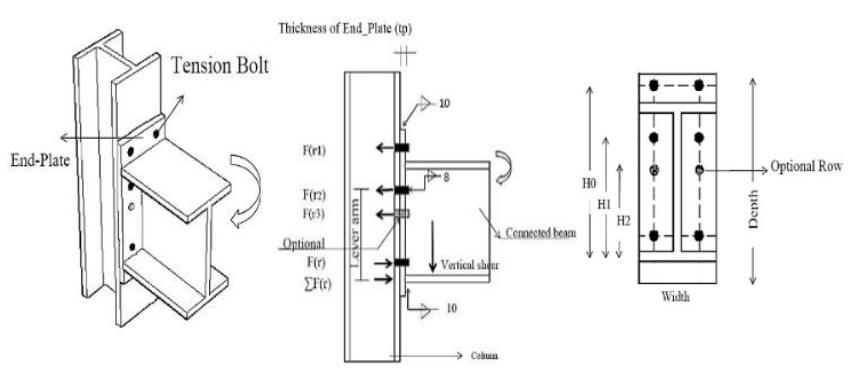

Fig. 10 Unstiffened EEP connection used in existing steel structures in Malaysia

The sizes of the column, beam, end-plate, and bolts are shown in Table 1. The specimens were categorized as EEP 1 to EEP 8. The end-plate widths varied from 200 to $250 \mathrm{~mm}$ and the number of tension bolt rows varied from two to three. The bolt size and thickness of the end-plate varied with the moment capacity of the connected beam.

Table 1

Properties of sections and EEP connections

\begin{tabular}{cccccccc}
\hline Specimen & Column sections & Beam sections & $\begin{array}{c}\text { Bolt size } \\
(\mathrm{mm})\end{array}$ & $\begin{array}{c}\text { Number of } \\
\text { rows in tension }\end{array}$ & Width & $\begin{array}{c}\text { Size of end-plate / SidePlate } \\
\text { Thickness } \\
\text { Depth } \\
(\mathrm{mm})\end{array}$ \\
\hline EEP 1 & HB $300 \times 300 \times 83.5$ & HB $500 \times 200 \times 102$ & 20 & 3 & 200 & 12 & 700 \\
\hline EEP 2 & HB $300 \times 300 \times 83.5$ & HB $500 \times 200 \times 102$ & 20 & 3 & 250 & 12 & 700 \\
\hline EEP 3 & HB $300 \times 300 \times 83.5$ & HB $500 \times 200 \times 102$ & 24 & 3 & 200 & 15 & 700 \\
\hline EEP 4 & HB $300 \times 300 \times 83.5$ & HB $500 \times 200 \times 102$ & 24 & 3 & 250 & 15 & 700 \\
\hline EEP 5 & HB $250 \times 250 \times 63.8$ & HB $450 \times 200 \times 65.1$ & 20 & 2 & 200 & 12 & 650 \\
\hline EEP 6 & HB $250 \times 250 \times 63.8$ & HB $450 \times 200 \times 65.1$ & 20 & 2 & 250 & 12 & 650 \\
\hline EEP 7 & HB $250 \times 250 \times 63.8$ & HB $450 \times 200 \times 65.1$ & 24 & 2 & 200 & 15 & 650 \\
\hline EEP 8 & HB $250 \times 250 \times 63.8$ & HB $450 \times 200 \times 65.1$ & 24 & 2 & 250 & 15 & 650 \\
\hline SidePlate & W $36 \times 395$ & W $40 \times 294$ & - & - & 1025 & 50 & 2000 \\
\hline
\end{tabular}

A hot-rolled I-shaped Perwaja Steel Section produced locally in Malaysia was used in this study in conformity with the British Standards Institute BS EN (EN 10113-3, 1993).

Table 2

Section properties

\begin{tabular}{|c|c|c|c|c|c|c|}
\hline Section & $\begin{array}{c}\text { Depth } \\
(\mathrm{mm})\end{array}$ & $\begin{array}{c}\text { Width } \\
(\mathrm{mm})\end{array}$ & $\begin{array}{c}\text { Flange Thickness } \\
(\mathrm{mm})\end{array}$ & $\begin{array}{c}\text { Web Thickness } \\
(\mathrm{mm})\end{array}$ & $\begin{array}{c}I_{x \times 1} \times 10^{8} \\
(\mathrm{~mm})^{4}\end{array}$ & $\begin{array}{c}M_{p} \\
(\mathrm{kN} . \mathrm{m})\end{array}$ \\
\hline HB 300 $\times 300 \times 83.5$ & 294 & 302 & 12 & 12 & 1.664 & 440 \\
\hline HB 500 $\times 200 \times 102$ & 506 & 201 & 19 & 11 & 5.5481 & 873 \\
\hline HB $250 \times 250 \times 63.8$ & 244 & 252 & 11 & 11 & 0.8703 & 124 \\
\hline HB $450 \times 200 \times 65.1$ & 446 & 199 & 12 & 8 & 2.8134 & 497 \\
\hline W36 × 395 & 960 & 427 & 55 & 30 & 114.5 & 9520 \\
\hline W40 294 & 1008 & 452 & 40 & 21 & 100.7 & 7857 \\
\hline
\end{tabular}

One test of the SidePlate moment connection was carried out to evaluate the adequacy of the proposed joint classification by AISC and EC3 for FR connections. In this connection type, a pair of parallel full-depth side plates has been incorporated to join the beam to the column (Fig. 11). The SidePlate moment connection has been designed in such a way as to guarantee that the connection deformation and energy dissipation mechanisms appear outside the connection components and the column itself. The connection between
Table 2 shows the section properties used in this study. 


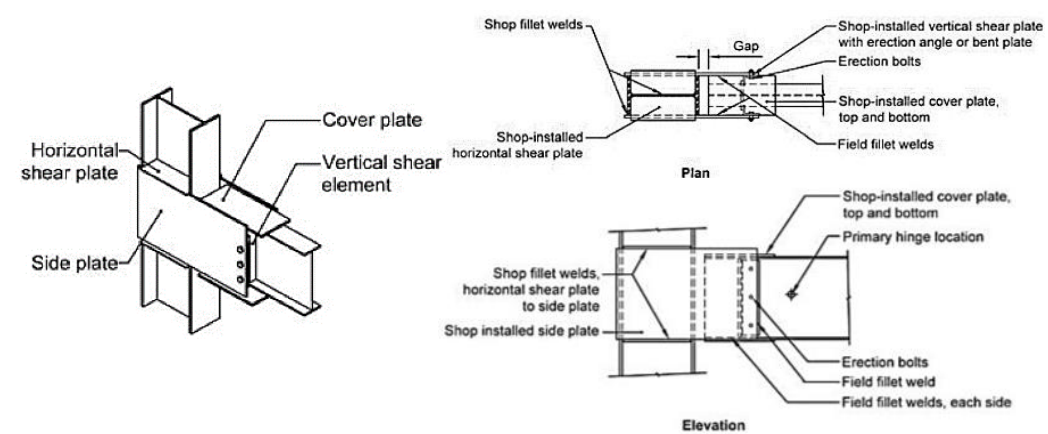

Fig. 11 Typical side plate moment connection system

\section{Results and Discussion}

The complete $\mathrm{M}-\theta$ curves for all eight EEP connections are shown in Fig. 12.

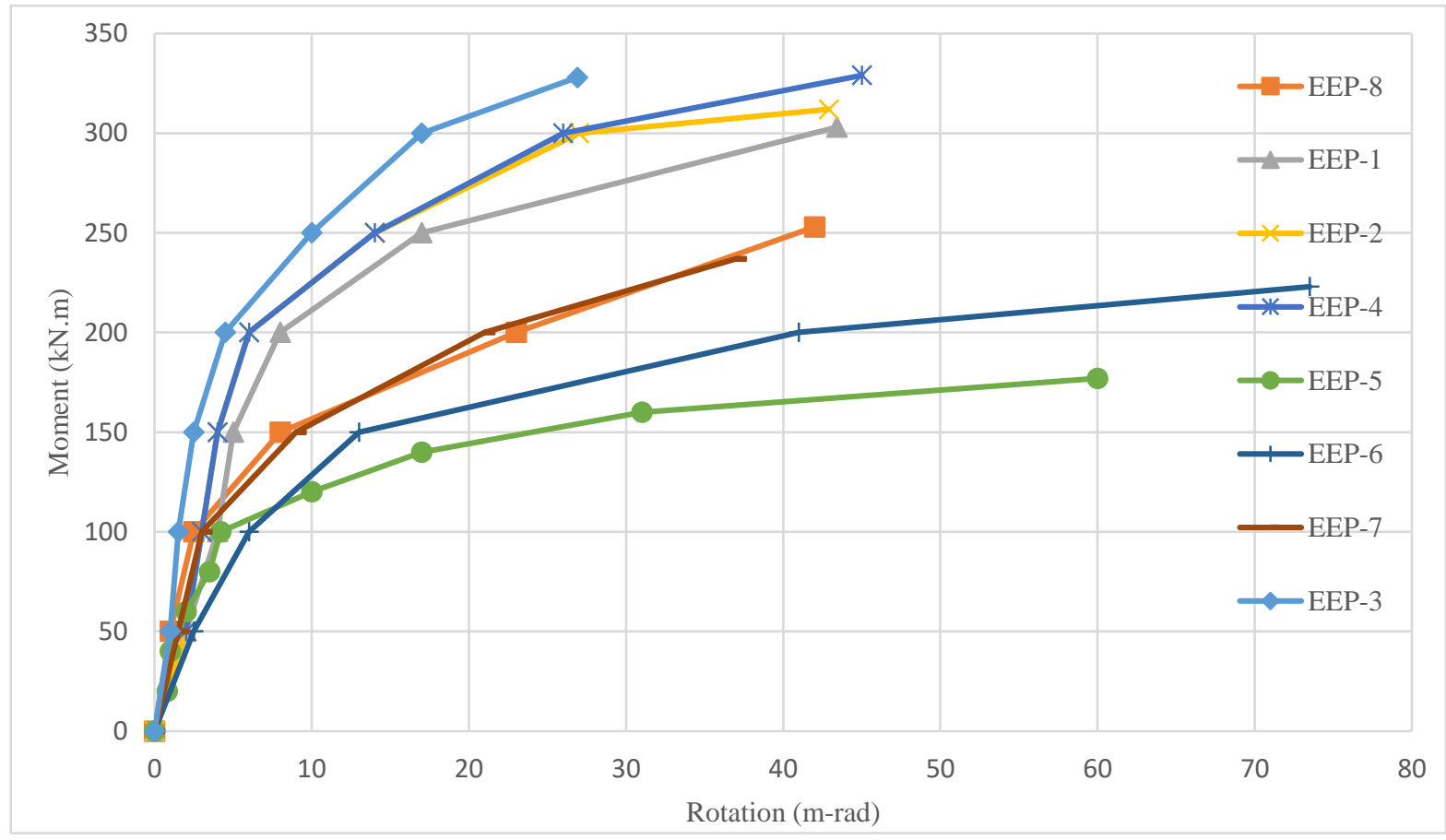

Fig. $12 \mathrm{M}-\theta$ curves of all EEP connections

In all of the tests, the specimens experienced nonlinearity early on in the first step of the loading sequence. The concentrated deformation appeared mainly in the tension area over the top bolt rows. The failure modes of the EEP connections, however, were dependent on the geometrical configuration. Two different failure modes were identified: (i) deformation of the end-plate and column flange in the tension zone and (ii) deformation of the end-plate

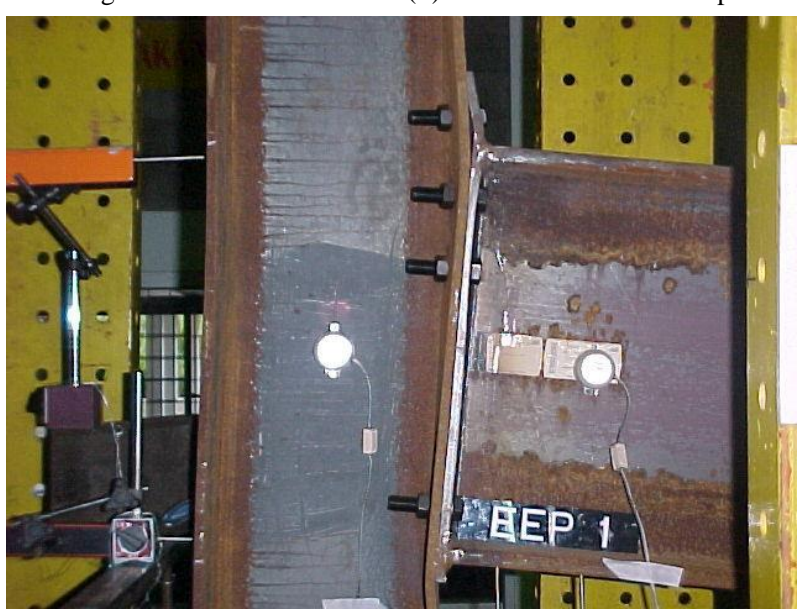

and column flange in the tension and compression zones. The modes of failure for all specimens are shown in Fig. 13. Generally, the results of the experimental test indicated that the size of bolts and thickness of the end-plate had negligible influences on the initial stiffness and $\mathrm{M}-\theta$ performance of the connections.

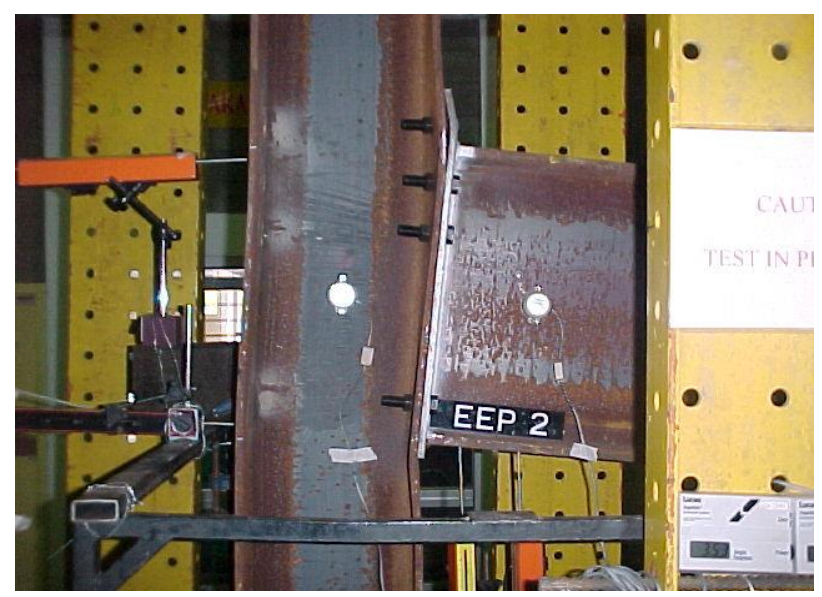



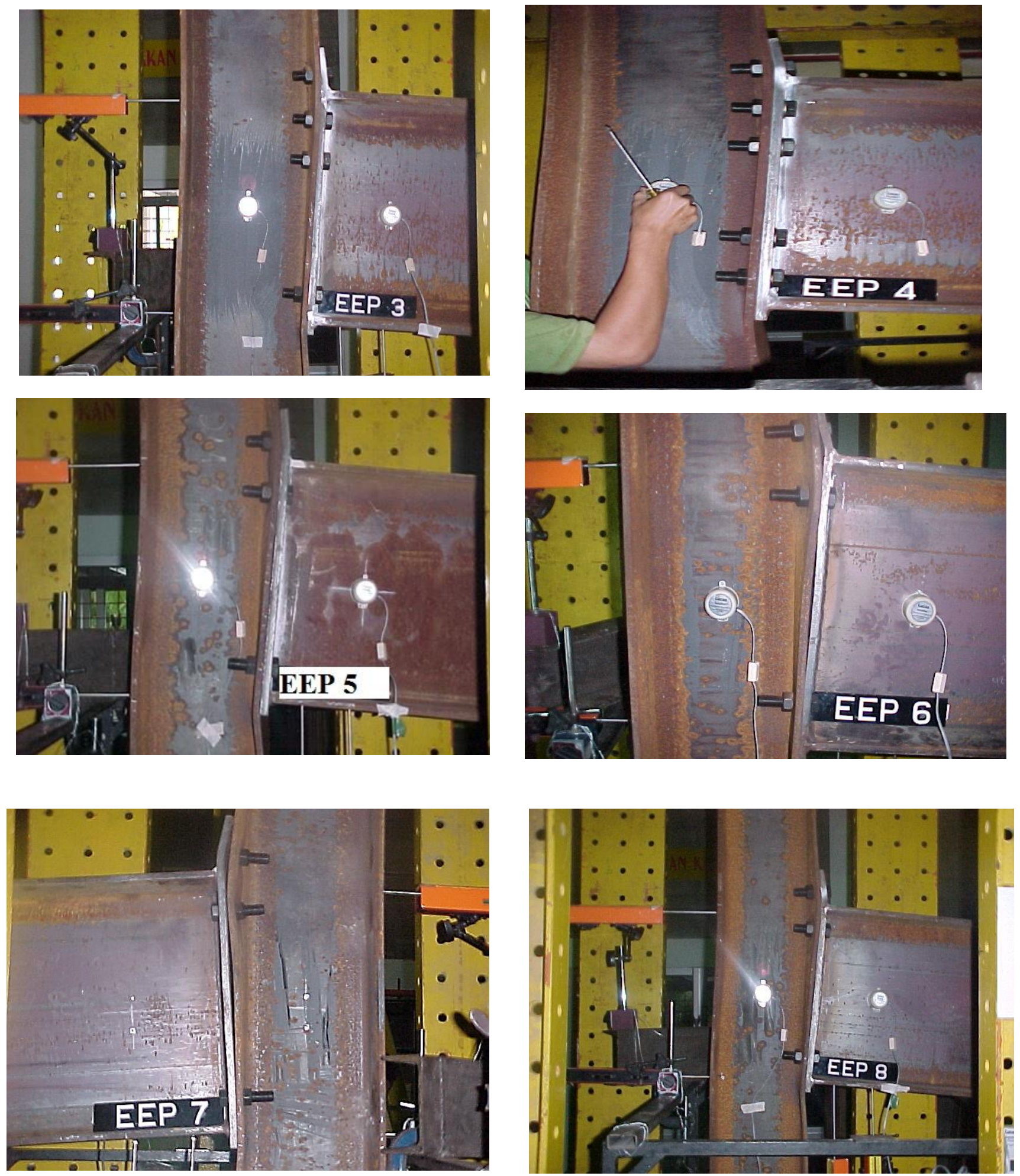

Fig. 13 Failure mode for all EEP connections

The $\mathrm{M}-\theta$ curve for the Side Plate moment connection is shown in Fig. 14. This figure clearly shows that this connection experienced very limited rotation compared to the EEP connection. However, it developed the full capacity of the connected beam. 


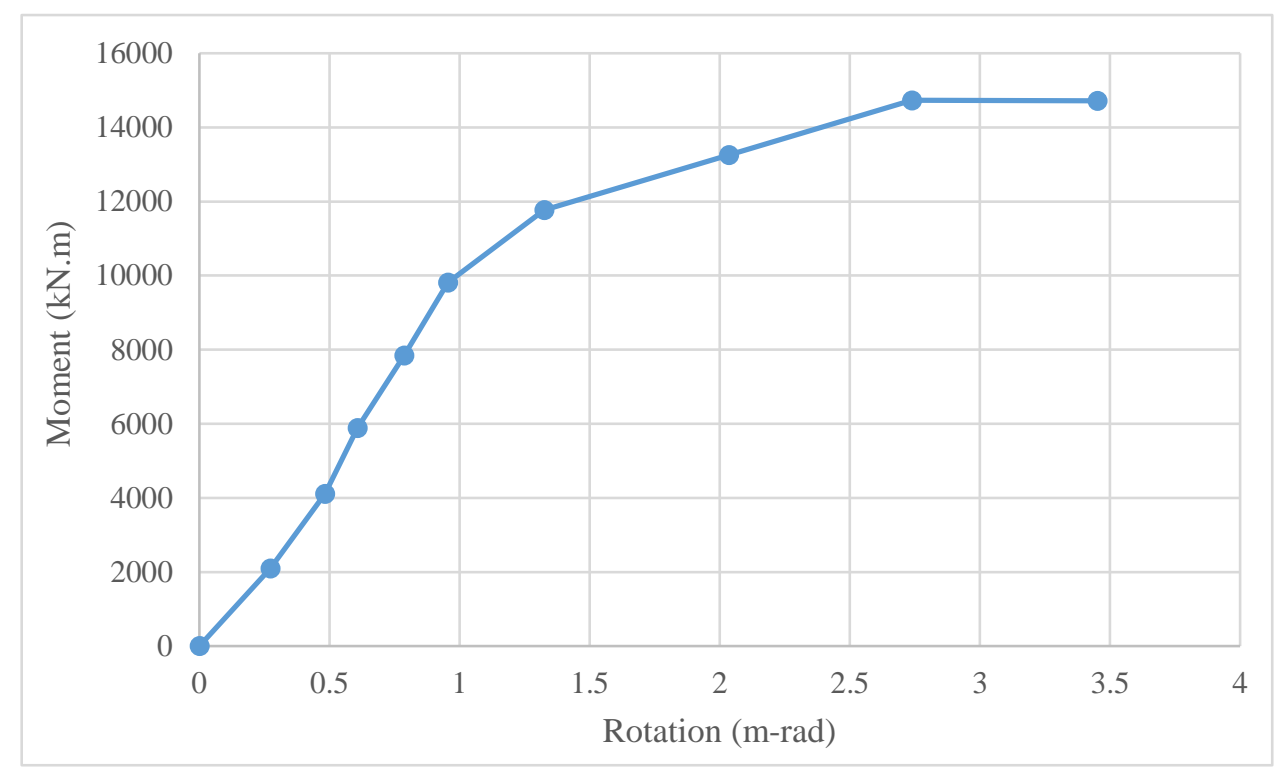

Fig. 14 M- $\theta$ Curve of side plate beam-to-column connection

In this specimen, plastic hinges appeared at the beam flanges under a vertical load of $10000 \mathrm{kN}$. After that, the beam flanges experienced a slight but visible buckling. In the next stages, the specimen showed full formation of the plastic hinge. The following failure sequence occurred: (i) plastic deformation, (ii) local buckling of beam flanges, and (iii) fracture initiation at the beam flanges with development into the web. The failure mode at the final stage of the test is shown in Fig. 15.

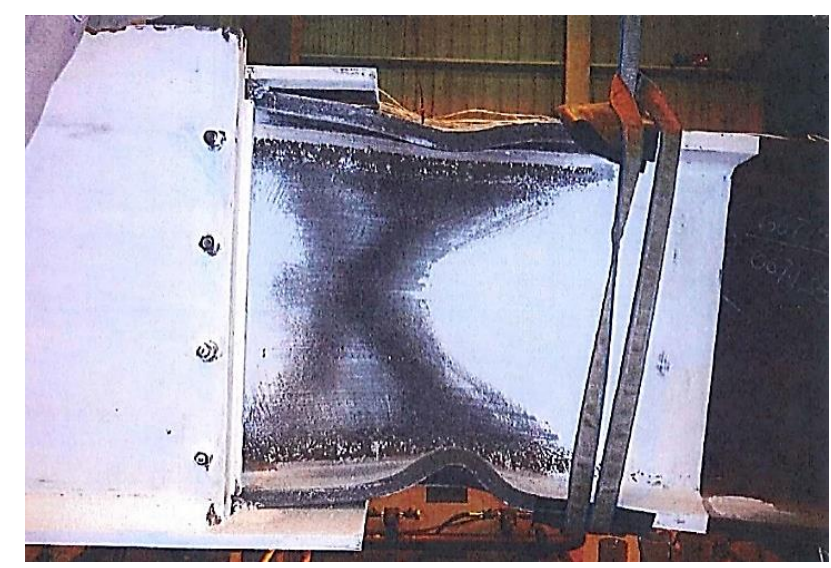

Fig. 15 Damaged state of side plate connection

\subsection{AISC Classification Overview}

Table 3 shows the calculated value of $\frac{k_{s} L}{E I}$ for both types of connections. The results indicate that all EEP connections should be categorized as flexible connections. For EEP 1 to EEP 4, the beams' flexural strength is twice that of the columns, and the connection performance is adversely affected, resulting in failure to develop the full capacity of the beam. The average ratio of the maximum connection capacity, $\mathrm{Mn}$, to the beam plastic moment, $\mathrm{Mp}$, beam, was 0.35 . However, all eight EEP connections transferred more than $20 \%$ of the beam plastic moment at a rotation of 0.02 radians. Table 3 also shows that the Side Plate moment connection possesses a higher value of $\frac{k_{s} L}{E L}$ than is recommended by AISC. This confirms that the SidePlate moment connection has enough stiffness to maintain continuity between the beam and column with negligible rotation. The results also showed that the Side Plate moment connection has a maximum moment capacity that is well in excess of the beam plastic moment. In the Side Plate, as the connection capacity significantly exceeds the beam capacity, the ductility of the whole system is controlled by the beam, and the connection remains elastic.

Table 3

Connection assessment based on AISC classification

\begin{tabular}{|c|c|c|c|c|c|c|c|c|}
\hline Specimen & $\begin{array}{c}M_{s} \\
(k N . m)\end{array}$ & $\begin{array}{c}M_{n} \\
(k N . m)\end{array}$ & $\begin{array}{l}\text { Mo.02 Rad } \\
(k N . m)\end{array}$ & $\begin{array}{c}\theta_{s} \\
\text { (radian) }\end{array}$ & $\begin{array}{c}\theta_{u} \\
\text { (radian) }\end{array}$ & $\begin{array}{l}M_{p, \text { Beam }} \\
(k N . m)\end{array}$ & $\begin{array}{l}K_{s} \\
\left(\frac{k N \cdot m m}{\text { radian }} \times 10^{6}\right)\end{array}$ & $\frac{k_{s} L}{E I}$ \\
\hline \multicolumn{9}{|c|}{ EEP connection } \\
\hline EEP 1 & 150 & 303.3 & 260 & 0.005 & 0.043 & 833.53 & 30.00 & 0.34 \\
\hline EEP 2 & 150 & 312.5 & 273 & 0.004 & 0.042 & 833.53 & 37.50 & 0.43 \\
\hline EEP 3 & 150 & 328.7 & 312.4 & 0.0025 & 0.027 & 833.53 & 60.00 & 0.69 \\
\hline EEP 4 & 150 & 329.2 & 275 & 0.003 & 0.045 & 833.53 & 50.00 & 0.58 \\
\hline EEP 5 & 80 & 177 & 145 & 0.0035 & 0.06 & 475 & 22.85 & 0.52 \\
\hline EEP 6 & 100 & 220 & 165 & 0.005 & 0.073 & 475 & 20.00 & 0.45 \\
\hline EEP 7 & 100 & 237 & 200 & 0.003 & 0.037 & 475 & 33.34 & 0.76 \\
\hline EEP 8 & 100 & 253 & 190 & 0.003 & 0.042 & 475 & 33.34 & 0.76 \\
\hline \multicolumn{9}{|c|}{ Side Plate connection } \\
\hline SP-1 & 5885.1 & 14712.6 & - & 0.006 & 0.00345 & 7269.5 & 9808.4 & 23.5 \\
\hline
\end{tabular}




\subsection{Overview of Eurocode 3 Classification}

Table 4 shows the initial rotational stiffness $\left(S_{j, \text { ini }}\right)$, component flexibilities $(\mathrm{Ki})$, and beam stiffness for both types of connections. The results indicated that all eight EEP connections can be categorized as semi-rigid connections based on their stiffnesses.

Table 4

Connection Assessment based on Eurocode Classification

\begin{tabular}{|c|c|c|c|c|c|}
\hline Specimen & $K_{l}$ & $K_{2}$ & $K_{e q}$ & $\begin{array}{c}\frac{E I_{b}}{L_{b}} \\
\left(\frac{k N \cdot m m}{\text { radian }} \times 10^{6}\right)\end{array}$ & $\begin{array}{c}S_{j, \text { ini }} \\
\left(\frac{k N . m m}{\text { radian }} \times 10^{6}\right)\end{array}$ \\
\hline \multicolumn{6}{|c|}{ EEP connection } \\
\hline EEP 1 & 3.4 & 5.3 & 5.3 & 84.9 & 60.1 \\
\hline EEP 2 & 3.4 & 5.3 & 3.36 & 84.9 & 52.8 \\
\hline EEP 3 & 3.4 & 5.3 & 6.65 & 84.9 & 73.7 \\
\hline EEP 4 & 3.4 & 5.3 & 4.3 & 84.9 & 67.6 \\
\hline EEP 5 & 2.3 & 5.4 & 3.46 & 43 & 45.2 \\
\hline EEP 6 & 2.3 & 5.4 & 2.96 & 43 & 42.4 \\
\hline EEP 7 & 2.3 & 5.4 & 4.35 & 43 & 49.6 \\
\hline EEP 8 & 2.3 & 5.4 & 3.95 & 43 & 47.1 \\
\hline \multicolumn{6}{|c|}{ Side Plate connection } \\
\hline SP-1 & $\infty$ & $\infty$ & - & 412.6 & 10850 \\
\hline
\end{tabular}

The EC3 classification only considers three types of beam-to-column connections, called welded, bolted angle flange cleat, and bolted end-plate connections, when calculating the initial rotational stiffness, $S_{j, i n i}$. EC3 only provides some general recommendations for other beam-to-column connections. Based on this regulation, the basic component flexibilities, K1 and $\mathrm{K} 2$, approach infinity in the presence of two parallel thick side plates. By substituting these two values in Eq. 7, the resulting initial rotational stiffness, $S_{j, i n i}$, was found to have an infinite value. Accordingly, the bilinear concept was assumed for determining the initial stiffness, Sj.ini, for the SidePlate moment connection. In this technique, the intercept constant moment, $\mathrm{Mi}$, was selected as the moment equivalent to the intersection of the moment axis and the strain hardening tangent stiffness line, which passes through the last point, as shown in Fig. 16. As a result, the intercept constant moment is highly dependent on the connection's ultimate moment [27]. Table 4 indicates that the SidePlate connection can be classified as a FR connection according to EC3, as the ratio of the initial stiffness to the beam stiffness was 26 .

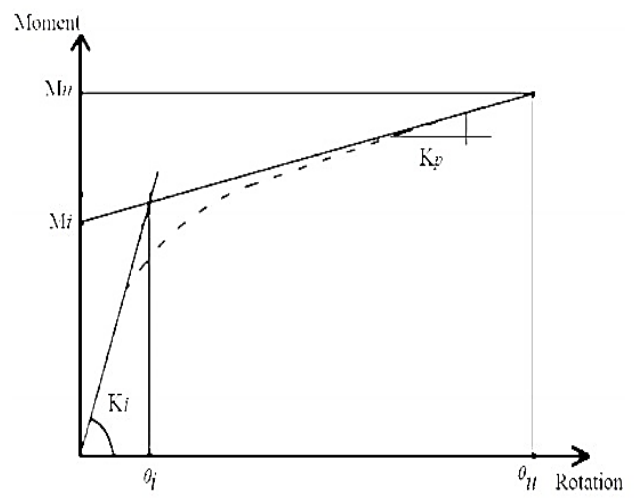

Fig. 16 Description of initial stiffness

\section{Development of a New Classification System}

The proposed classification was developed based on the connection strength, stiffness, and ductility requirements. Accordingly, the proposed system considered three groups, that is, (i) flexible, (ii) FR, and (iii) semirigid.

\subsection{Boundaries Based on Rigidity and Ultimate Strength Level}

To classify connections based on rigidity, the initial rotational stiffness, $S_{j, \text { ini }}$, is considered along with the connected beam rigidity. EC3 considers values of 25 and 8 as the boundary limitations of rigid to semi-rigid connections for unbraced and braced frames, respectively. To validate these proposed values, it is important to examine one-story moment and braced frames, as shown in Fig. 17.

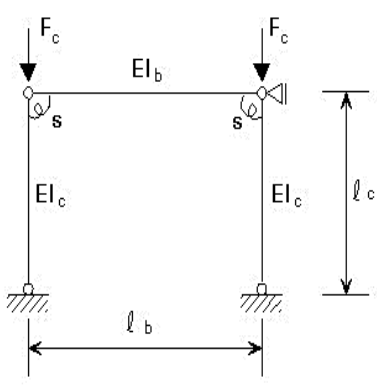

Braced frame

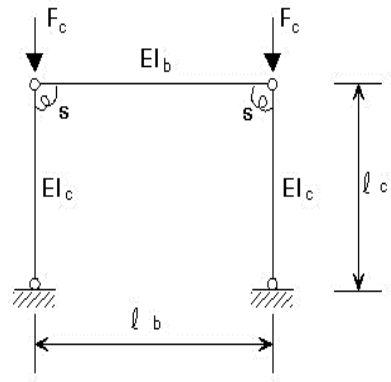

Unbraced frame
Fig. 17 Single-Story braced and unbraced frames

Fig. 18 shows the relationship between the relative beam-to-column rigidity $\rho$ and relative connection-to-beam rigidity $\bar{S}$. Fig. 18 indicates that for the moment frame, the flexibility of the connection decreases the Euler buckling load.

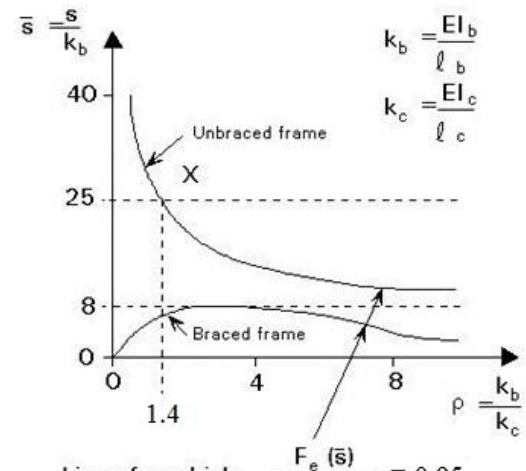

Lines for which $\frac{F_{e}(\bar{s})}{F_{e}(\bar{s}=\infty)}=0.95$ 
EC3 proposes a boundary $\rho$ value of 1.4 for unbraced frames. It is believed that values of $\rho \geq 1.4$ do not satisfy the beam-to-column connection ratio prescribed by the AISC 341-10 seismic provisions for structural steel buildings for special moment frames. Besides, $\rho<1.4$ is non-conservative, as shown in Fig. 19. Fig. 19 indicates that when $\rho=0.1$, the buckling load based on $\bar{S}=25$ is $85 \%$ of the buckling load for $\bar{S}=\infty$. Accordingly, $\bar{S}=25$ is a suitable boundary value for moment frames to be considered as FR.

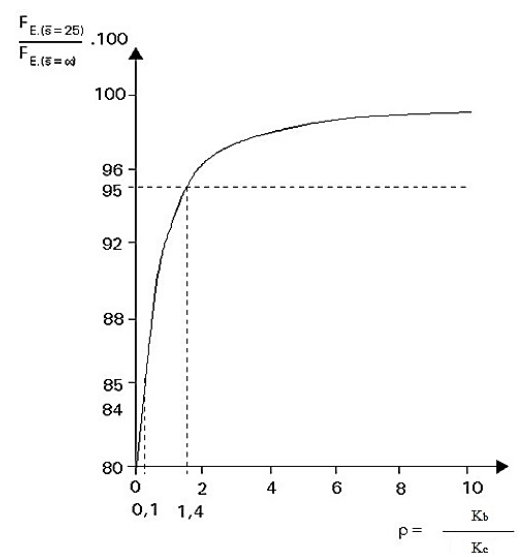

Fig. 19 Relationship between $\rho$ and the Euler Buckling Load

The data in Table 3 show that the use of a moment capacity of 0.38 MP is adequate for the flexible to semi-rigid boundaries. For FR boundaries, however, the ultimate bending moment is higher than $0.6 \mathrm{MP}$, or perhaps even higher than the beam plastic moment MP. Besides, the proposed boundary classification uses the value of the relative connection-to-beam rigidity, $\bar{S}$, of 25 proposed by EC3. The proposed boundary classification is developed based on the ratio of $\mathrm{Mn}$ to $\mathrm{Mp}$, beam and the ratio of the beam rigidity $\frac{E I_{b}}{L_{b}}$ to Mp,beam, given as

$m=\frac{M_{n}}{M_{\text {p beam }}}$
$\phi=\frac{E I_{b}}{L_{b} M_{p \text { beam }}} \times 10^{-3}$

Fig. 20 shows the proposed boundary classification diagram for unbraced frames. The boundary for rigid to semi-rigid connections is developed based on the following assumptions:

When

$$
\phi \leq 0.025 \quad m \geq 25 \phi
$$

When

$0.025<\phi \leq 0.15 \quad m \geq \frac{25 \phi+3.25}{7}$

The boundary for semi-rigid to flexible connections is developed based on the following assumptions:

When

$\phi \leq 0.05 \quad m \geq 5 \phi$

When

$0.05<\phi \leq 0.15 \quad m \geq \frac{5 \phi+2}{7}$

The boundaries in Fig. 20 are trilinear rather than bilinear, based on the following justifications:

i. The experimental results indicated that a connection possesses linear behaviour up to two-thirds of its maximum moment capacity, $M_{n}$.

ii. The beam also behaves linearly above two-thirds of the ultimate moment capacity, $M_{n}$, but with a much lower slope. Plasticity in beams with I-sections starts at about $W_{e} / W_{p l}=0.9$, theoretically.

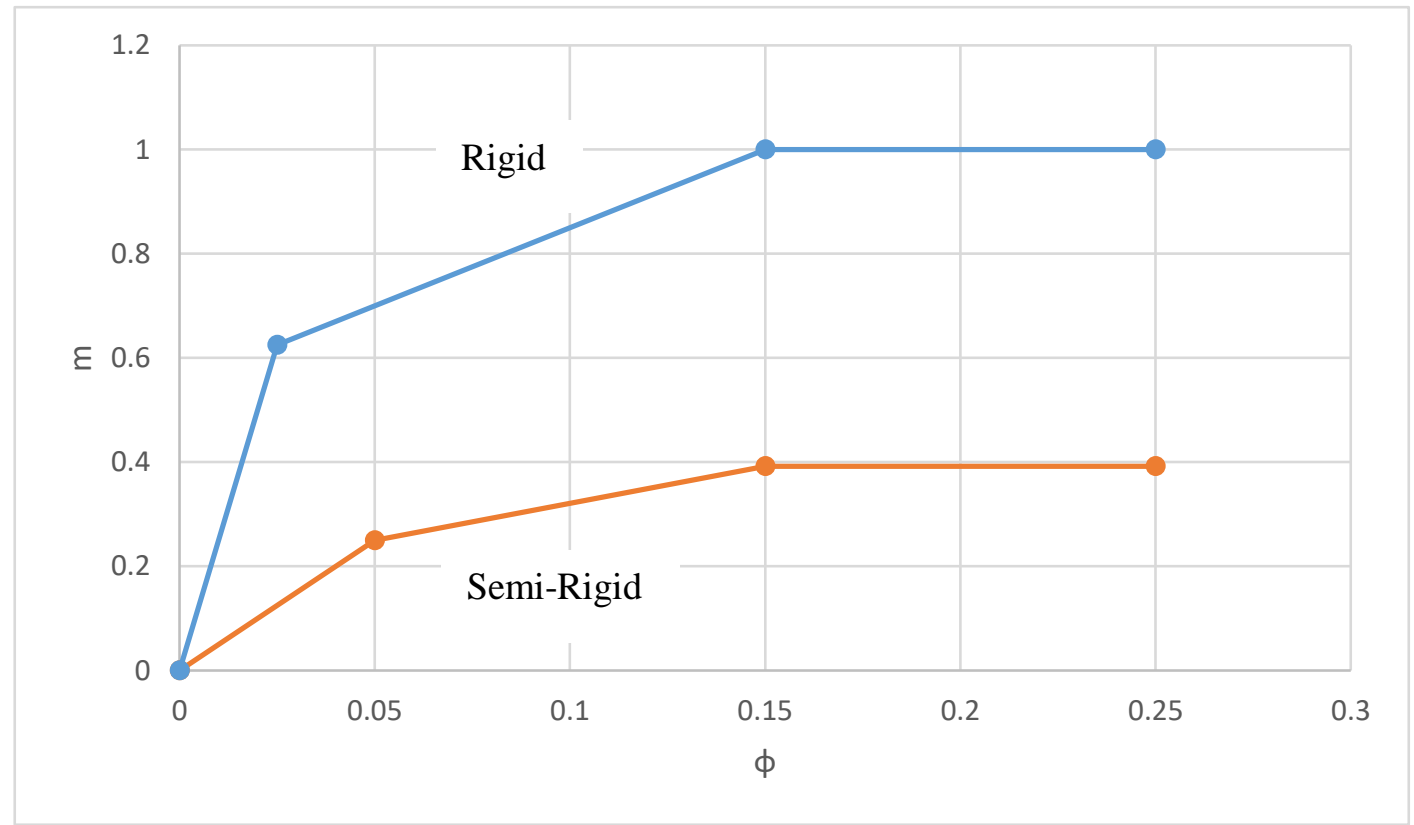

Fig. 20 Boundary classifications for connections in unbraced frames based on their rigidities 
Fig. 21 shows that all eight EEPs are categorized as semi-rigid connections while the SidePlate connection is classified as a rigid connection. Fig. 21 also shows that the proposed boundary classification predicted conservative results for SidePlate. This issue can be explained by the fact that SidePlate is representative of hyper-strength connections that have moment resistance that is truly higher than the plastic moment of the connected beam.

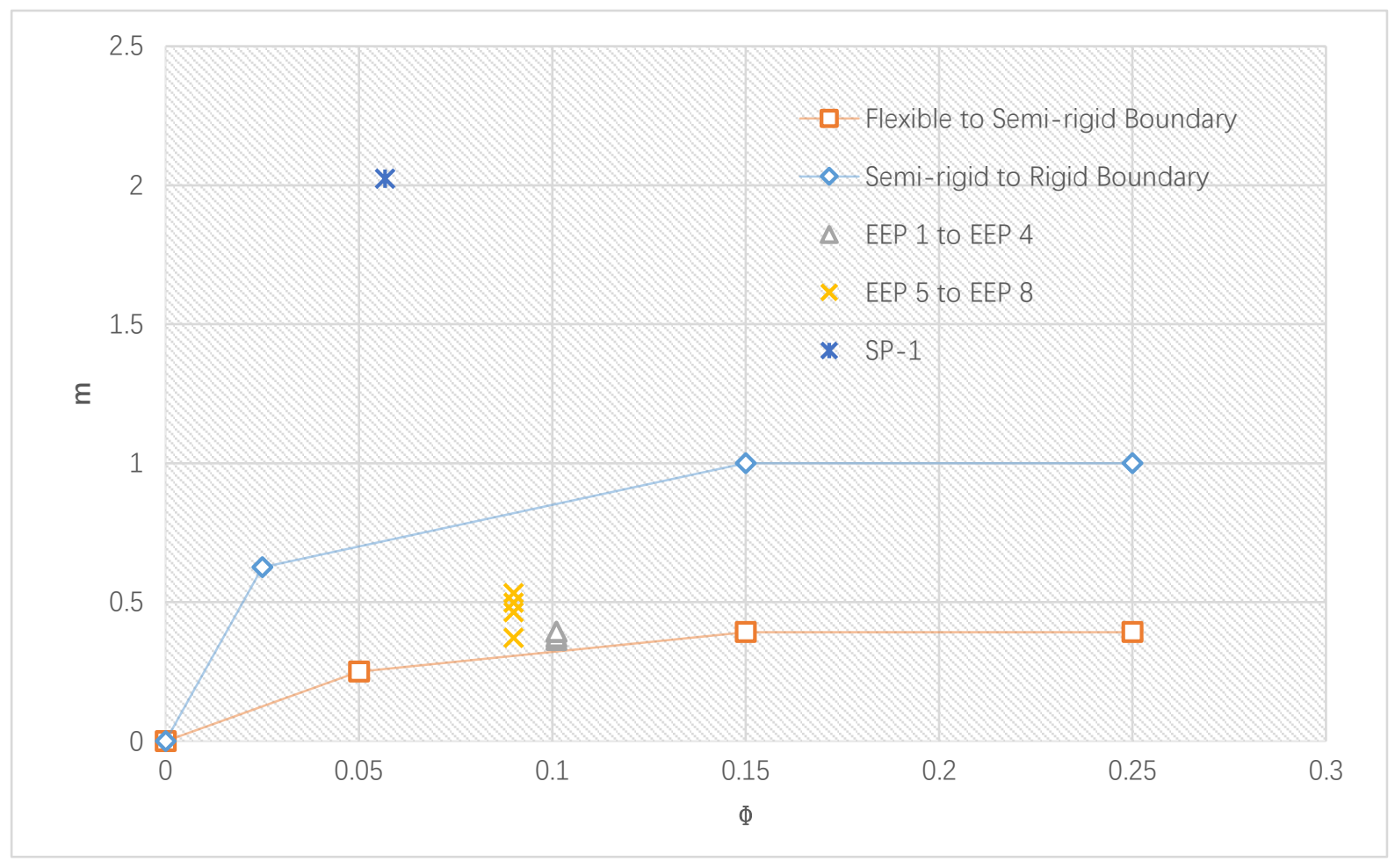

Fig. 21 Comparison between the test results and the proposed boundaries classification

It is recommended that the beam length be selected so that the initial stiffness of the beam matches that of the connection. In other words, the initial $M-\theta$ curve slope, $C_{c}$, of the connection should match the beam stiffness $E I_{b} / L_{b}$. Kishi and Chen [3] evaluated a variety of beam-to-column connections to find the most appropriate beam length. Table 5 shows the reference length and the ultimate moment developed for a total of 55 different connections proposed by Kishi and Chen; however, it is not clear whether or not these data considered shear panel zone effects. Table 5 also shows that stiff connections demand a shorter equivalent reference length. In other words, a shorter length is required for stiffer connections to match the beam stiffness (i.e., $C=C_{c}$ ). The findings of this study are consistent with those of Kishi and Chen, showing that a value of $l_{e}=3 d$ would be suitable for an EEP and a value of $l_{e}$ $=1.2 d$ would be appropriate for SidePlate connections if the shear panel zone effects are considered $(d=$ depth of beam).

Table 5

Reference lengths for different steel beam-to-column connections

\begin{tabular}{|c|c|c|c|c|c|}
\hline \multirow[b]{2}{*}{ Description } & \multirow{2}{*}{$\begin{array}{c}\text { Rigid connections } \\
\text { Bolted stiffened EEP }\end{array}$} & \multicolumn{2}{|c|}{ Semi-rigid connections } & \multicolumn{2}{|c|}{ Flexible connections } \\
\hline & & $\begin{array}{c}\text { Flush } \\
\text { end-plate }\end{array}$ & $\begin{array}{l}\text { Top/seat } \\
\text { angles and } \\
\text { web angle }\end{array}$ & $\begin{array}{l}\text { Header } \\
\text { plate }\end{array}$ & $\begin{array}{l}\text { Double } \\
\text { web } \\
\text { angles }\end{array}$ \\
\hline Equivalent length $l_{e}$ & $1 d<l_{e}<2 d$ & $2 d<l_{e}<5 d$ & $4 d<l_{e}<7 d$ & $\cong 10 d$ & $\cong 15 d$ \\
\hline Ultimate moment $M_{u}$ & $\cong 0.9 M_{p}$ & $\cong 0.6 M_{p}$ & $\cong 0.45-0.6 M_{p}$ & $\cong 0.2 M_{p}$ & $\cong 0.15 M_{p}$ \\
\hline
\end{tabular}

\subsection{Boundaries Based on the Ductility Requirement}

The ductility requirement for classification purposes was calculated based on the following equation:

$\theta_{R}=k \theta_{u}$

Where

$\theta_{u}$ is the theoretical plastic rotation of the connection calculated as follows and shown in Fig. 22:

$\theta_{u}=\frac{M_{n}}{C_{c}}$

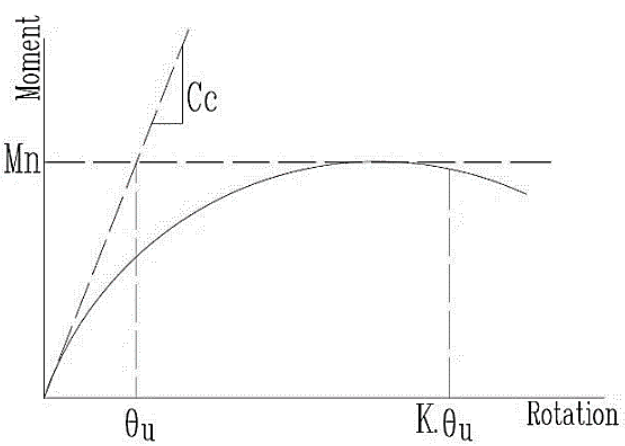

Fig. 22 Definition of the required ductility for the connection

The value of $\mathrm{k}$ is a function of the code requirements, frame type, and location seismicity. The AISC specification proposes a $\mathrm{k}$ value of 4 for medium seismic requirements. The initial stiffness, $C_{c}$, of the beam-tocolumn connections is calculated as: 
$C_{c}=\frac{(E I)}{a d}$

where

$a$ is the equivalent length factor of the connected beam according to Table 5 (1 15), which makes the beam stiffness match the connection stiffness.

The non-dimensional ductility requirement, $\bar{\theta}_{R}$, is calculated based on the following equation:

$\overline{\theta_{R}}=\frac{\theta_{R}}{\theta_{p}}$

where $\theta_{p}$ is the theoretical plastic rotation of the connected beam using the plastic moment and a value of $3 \mathrm{~d}$ that represents the reference length factor (average equivalent reference length between the EEP and SidePlate connection)

Therefore, $\theta_{p}$ for the EEP connection is calculated as follows:

$\theta_{p}=\frac{M_{p}}{\left(\frac{E I}{3 d}\right)}$

The following equation shows the development of the required nondimensional ductility, $\bar{\theta}_{R}$ :

$\overline{\theta_{R}}=\frac{\theta_{R}}{\theta_{p}}=k M_{n}\left(\frac{a d}{E I}\right)\left(\frac{E I}{3 d}\right) \frac{1}{M_{p}}=\left(\frac{k}{3}\right)\left(\frac{M_{n}}{M_{p}}\right) a$

Finally, by substituting Eq. 17 into Eq. 20, the non-dimensional ductility requirement, $\bar{\theta}_{R}$, is calculated as follows:

$\overline{\theta_{R}}=\left(\frac{k}{3}\right)\left(\frac{M_{n}}{M_{p}}\right)\left(\frac{E I}{C_{c} d}\right)$

Eq. 21 indicates that the non-dimensional ductility requirement, $\bar{\theta}_{R}$, is influenced by the ratio of the ultimate moment capacity of the connection, $M_{n}$, to the beam plastic moment, $M_{p}$. It has an adverse relationship with the initial stiffness of the connection $C_{c}$. In other words, flexible connections demand higher ductility. Fig. 23 shows the connection strength boundaries as well as the non-dimensional ductility requirement, $\bar{\theta}_{R}$, line. By solving Eq. 21 and using data from Table 5 , the non-dimensional ductility requirement, $\bar{\theta}_{R}$, can be drawn.

Fig. 23 shows that the idealized line intersects the plastic strength boundary at a value of $\bar{\theta}_{R}=1.35$ (FR connection) and the non-dimensional ductility requirement at a value of $\bar{\theta}_{R}=2.5$ (flexible connection). Fig. 23 also indicates that the proposed non-dimensional ductility boundary line provides an acceptable prediction in comparison with the experimental test results.

\section{Summary and Conclusions}

This paper has presented an investigation of the connection classification index proposed by AISC and Eurocode 3. A test programme was conducted to evaluate the static $M-\theta$ characteristics of the EEP representative of semirigid connections. Initial stiffnesses and complete $M-\theta$ curves were evaluated for connections with different geometries. According to the experimental and theoretical results, the following conclusions were drawn:

i. AISC provided a conservative boundary limitation for flexible to semi-rigid connections considering the results of classical methods.

ii. The experimental $M-\theta$ curves indicated that all EEP connections experienced large rotation. Consequently, this flexible performance should be addressed in the analysis process of the whole structure. It is also important to recognize that the flexibility of connections resulted from large second-order $(P-\Delta)$ effects in the whole structure that should be considered in the analysis process.

iii. Eurocode 3 provided a reliable classification index in which the initial rotational stiffnesses $\left(S_{j, i n i}\right)$ were adequately predicted compared to those obtained from the bilinear concept.

iv. Experimental test results showed that the size of bolts and thickness of the end-plate had a negligible influence on the initial rotational stiffness of the EEP beam-to-column connection.

v. The beam-to-column flexural capacity ratio should satisfy the AISC seismic requirements [28]. Furthermore, the design criteria should provide sufficient strength in the elements of the connections to ensure that the inelastic deformation of the connection is achieved by beam yielding.

vi. According to the proposed classification system, the flexibility of semi-rigid connections should be taken into account in the global analysis of the structure. In general terms, semi-rigid connections are not recommended for unbraced frames due to the extensive horizontal deformation which may cause problems in the overall stability. However, for braced frames, the introduction of semirigid connections may lead to more economical results due to the optimisation of the steel material for the beams.

vii. When analysing semi-rigid frames, the behaviour of the joint needs to be modelled; this is associated with a mathematical model of the $M-\theta$ curve considering the connection strength, stiffness, and ductility characteristics. Therefore, one of several $M-\theta$ curve representations including linear, bilinear, multilinear, and nonlinear should be used in the analysis procedure. The most accurate representation can be obtained using continuous nonlinear functions such as the $M-\theta$ curves resulting from this study for EEP and SidePlate connections, although the multilinear representation is commonly used.

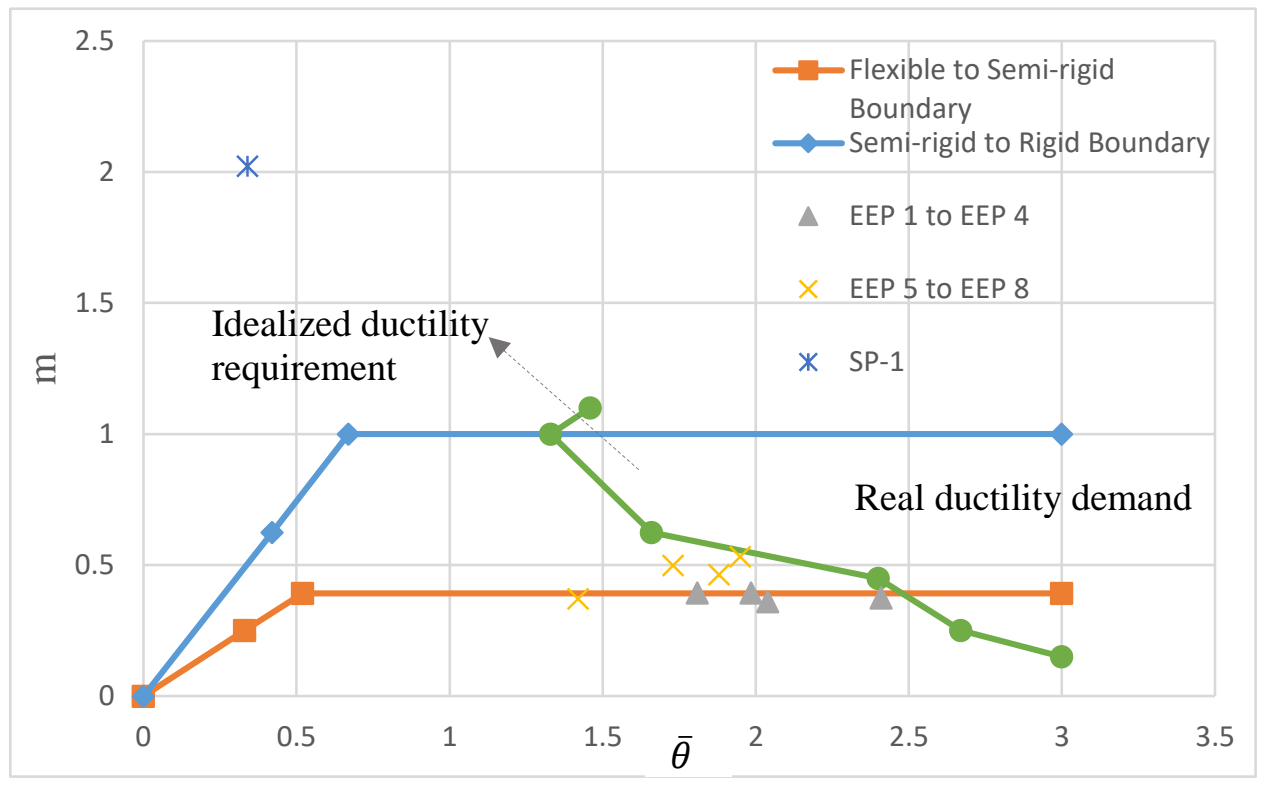

Fig. 23 Non-dimensional ductility requirement boundary 


\section{Acknowledgements}

The authors wish to thank the esteemed technical staff of the Laboratory of Structures and Materials, Universiti Teknologi Malaysia (UTM), for their cooperation and support in this study. The financial support provided under the High Impact Research Scheme vote number Q.J130000.2409.04G50 provided by the Institute for Smart Infrastructure and Innovative Construction, Universiti Teknologi Malaysia, was invaluable for conducting the experimental work, and authors shall remain acknowledged.

\section{References}

[1] Specification for Structural Steel Buildings (ANSI/AISC 360-10), A.I.O.S. Construction, Editor. 2010, AISC Committee on Specifications.

[2] Eurocode 3: Design of Steel Structures - Part 1-8: Design of Joints. 2005, European Committee For Standardization.

[3] Kishi N., et al., "Study of Eurocode 3 steel connection classification", Engineering Structures, 19(9), 772-779, 1997.

[4] Nethercot D., Li T. and Ahmed B., "Unified classification system for beam-to-column connections", Journal of Constructional Steel Research, 45(1), 39-65, 1998.

[5] Bjorhovde R., Colson A. and Brozzetti J., "Classification system for beam-to-column connections", Journal of Structural Engineering, 116(11), 3059-3076, 1990.

[6] Chen W.F. and Kishi N., "Semirigid steel beam-to-column connections: Data base and modeling", Journal of Structural Engineering, 115(1), 105-119, 1989.

[7] Zahmatkesh F., et al., "Numerical Study on the Structural Performance of Steel Beams with Slant End-plate Connections", Latin American Journal of Solids and Structures, 13(7), 1360-1387, 2016

[8] Wang W. and Chen Y., "Modelling and classification of tubular joint rigidity and its effect on the global response of CHS lattice girders", Structural Engineering and Mechanics, 21(6), 677-698, 2005

[9] Chan S.L., "Geometric and material non-linear analysis of beam-columns and frames using the minimum residual displacement method", International Journal for Numerical Methods in Engineering, 26(12), 2657-2669, 1988.

[10] Yu J. and Hao J., "Behaviour of semi-rigid steel frames with steel plate shear walls", ISSN 1816-112X, 115(1), 154, 1989.

[11] Jones S., Kirby P. and Nethercort D., "The analysis of frames with semi-rigid connections-a state-of-the-art report", Journal of Constructional Steel Research, 3(2), 2$13,1983$.
[12] Jones S., Kirby P. and Nethercot D., "Effect of semi-rigid connections on steel column strength", Journal of Constructional Steel Research, 1(1), 38-46, 1980

[13] Simoes L., "Optimization of frames with semi-rigid connections", Computers and Structures, 60(4), 531-539, 1996.

[14] Lee S.S. and Moon T.S., "Moment-rotation model of semi-rigid connections with angles", Engineering Structures, 24(2), 227-237, 2002.

[15] Bayo E., Cabrero J. and Gil B., "An effective component-based method to model semirigid connections for the global analysis of steel and composite structures", Engineering Structures, 28(1), 97-108, 2006.

[16] Kartal M., et al., "Effects of semi-rigid connection on structural responses", Electronic Journal of Structural Engineering, 10(10), 22-35, 2010

[17] Talebi E., et al., A Numerical Analysis on the Performance of Buckling Restrained Braces at Fire-Study of the Gap Filler Effect, Steel and Composite Structures, an International Journal (In Press), 2015.

[18] Saravanan M., et al., "Advanced analysis of cyclic behaviour of plane steel frames with semi-rigid connections", Steel and Composite Structures, 9(4), 381-395, 2009.

[19] Chan S.L. and Chui P.T., "Non-linear Static and Cyclic Analysis of Steel Frames with Semi-Rigid Connections", Elsevier, 2000.

[20] Díaz C., et al., "Optimum design of semi-rigid connections using metamodels", Journal of Constructional Steel Research, 78, 97-106, 2012.

[21] Zahmatkesh F. and Talebi E., The Performance of Bolted Slant Endplate Connections Subjected to Temperature Increase", Proceedings of the 10th Biennial Conference on Engineering Systems Design and Analysis (ESDA'10), 2010.

[22] Nguyen P.C. and Kim S.E., "An advanced analysis method for three-dimensional stee frames with semi-rigid connections", Finite Elements in Analysis and Design, 2014, 80 , 23-32, 2014

[23] Brunesi E., Nascimbene R. and Rassati G., "Response of partially-restrained bolted beamto-column connections under cyclic loads", Journal of Constructional Steel Research, 97 , 24-38, 2014.

[24] Geschwindner L.F., "A simplified look at partially restrained beams", Engineering Journal/American Institute of Steel Construction, 28(2), 73-78, 1991.

[25] Hsieh S.H. and Deierlein G., "Nonlinear analysis of three-dimensional steel frames with semi-rigid connections", Computers \& Structures, 41(5), 995-1009, 1991.

[26] Kukreti A., Murray T. and Abolmaali A., "End-plate connection moment-rotation relationship", Journal of Constructional Steel Research, 8, 137-157, 1987.

[27] Latour M., Piluso V. and Rizzano G., "Experimental behaviour of friction T-stub beamto-column joints under cyclic loads", Steel Construction, 6(1), 11-18, 2013.

[28] Seismic Provisions for Structural Steel Buildings A.I.O.S. Construction, Editor. 2010, AISC committee on Specifications. 